\title{
Árboles del Valle Central de Costa Rica: reproducción guachipelín (Diphysa americana (Mill.) M. Sousa)
}

\author{
Trees of the Central Valley of Costa Rica: reproduction Guachipelín (Diphysa americana \\ (Mill.) M. Sousa)
}

Freddy Rojas-Rodríguez • Gustavo Torres-Córdoba²

\begin{abstract}
The following issue presents a brief description about the "Guachipelín" tree (Diphysa americana (Mill.) M. Sous), including information about its phenology which directly relates to fruit recollection, seed treatment, nursery, and germination processes.
\end{abstract}

Keywords: Phenology, seeds treatments, management at nursery, germination, trees.

\section{Resumen}

Se presenta una breve descripción del árbol "Guachipelín" (Diphysa americana (Mill.) M. Sousa), información sobre fenología como base para la recolección de frutos, el manejo de las semillas, la viverización y el proceso de germinación.

Palabras clave: Fenología, manejo de semillas, viverización, germinación, árboles.

1. Consultor Independiente; Cartago, Costa Rica; freddyrojasrodriguez@gmail.com

2. Tecnológico de Costa Rica, Escuela de Ingeniería Forestal;

Cartago, Costa Rica; gtorres@tec.ac.cr; (+506) 2550- 2039
Recibido: 26/09/2018

Aceptado: 01/12/2018

Publicado : 26/09/2018

Doi: $10.18845 /$ rfmk.v16i38.3998 


\section{Taxonomía}

Nombre científico: Diphysa americana (Mill.) M. Sousa

Nombre común: Guachipelín

Familia: Fabaceae-Papilionaceae

Origen: Nativa

Distribución en el mundo: Desde México hasta Panamá.

Distribución en Costa Rica: En Costa Rica es frecuente en la costa pacífica hasta el Valle Central.

\section{Descripción}

Árbol mediano, caducifolio, de copa extendida e irregular. El fuste es generalmente negruzco, retorcido, muy fisurado y ramificado a baja altura. La corteza es llamativa y con largas fisuras verde amarillentas, que contrastan con el color café oscuro de la corteza interna, con lomos prominentes y muy áspera.

Las hojas son imparipinnadas, alternas, presentan frecuentemente de 9 a 21 hojuelas membranáceas, verde brillante en la superficie superior, pálidas por debajo, de 1,5 a $3,5 \mathrm{~cm}$ de largo.

Las flores son amarillas, muy vistosas, en racimos axilares, muy atrayentes, cubren completamente el árbol al final de la época lluviosa.

Su floración es una fuente de néctar y de polen, siendo esta especia visitada por abejas grandes (de las llamadas carpinteras [1].

Produce frutos secos tipo vaina indehiscente de aproximadamente $8 \mathrm{~cm}$ de largo (figura 1), con un mimetismo espectacular pues parecen hojas secas protegen las semillas de manera tal que a veces se cree que son vanas. Son muchas veces infladas, su cubierta exterior es delgada, papirácea y quebradiza.

Las semillas son comprimidas de forma ovoide, carnosas de 0,7 a $1 \mathrm{~cm}$ de largo y aproximadamente de $0,3 \mathrm{~cm}$ de grosor. De color crema claro. Su embrión se localiza en el extremo más delgado con una forma curva muy particular [2].

Esta es una especie importante para la rehabilitación de suelos y como alternativa ecológica en el manejo de cuencas hidrográficas, al estabilizar los cauces fluviales y proteger los mantos acuíferos [3].

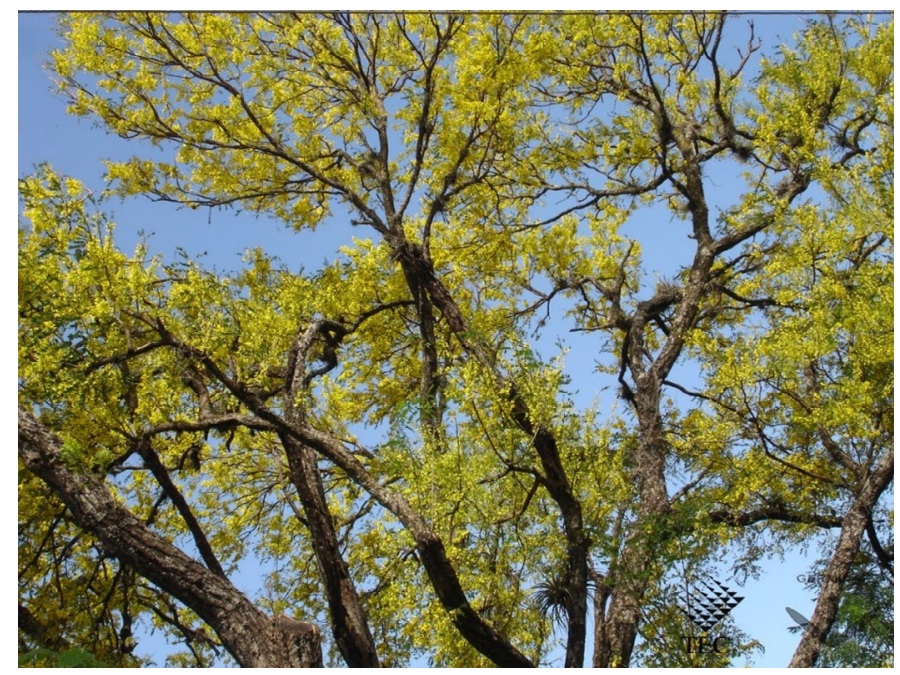

Figura 1. Perfil de Guachuipelín.

Figure 1. Profile of "Guachipelin" tree.

\section{Dendrofenocronograma}

Se presenta a continuación información fenológica de guachipelín, para el Valle Central de Costa Rica.

Cuadro 1. Dendrofenocronograma del Guachipelín en el Valle Central, Costa Rica.

Table 1. Tree phenology through time in Guachipelín, Central Valley, Costa Rica.

\begin{tabular}{|c|c|c|c|c|c|c|c|c|c|c|c|c|}
\hline \multirow{2}{*}{ Características } & \multicolumn{12}{|c|}{ Meses del año } \\
\hline & $\mathrm{E}$ & $F$ & $\mathrm{M}$ & A & $\mathrm{M}$ & $\mathrm{J}$ & $\mathrm{J}$ & A & $S$ & 0 & $\mathrm{~N}$ & D \\
\hline \multicolumn{13}{|l|}{ Hojas } \\
\hline Flores & & & & & & & & & & & & \\
\hline Frutos verdes & & & & & & & & & & & & \\
\hline Frutos maduros & & & & & & & & & & & & \\
\hline
\end{tabular}

\section{Manejo de semilla y viverización}

Los frutos de guachipelín se recolectan, en el Valle Central de Costa Rica, entre los meses de enero y mayo. La madurez de sus frutos se reconoce tanto por su color café claro como por su dispersión que es de tipo anemócora (por viento). La recolección de estos preferiblemente debe hacerse mediante el uso de podadora de extensión y manta para su posterior embalaje al vivero [2]. 


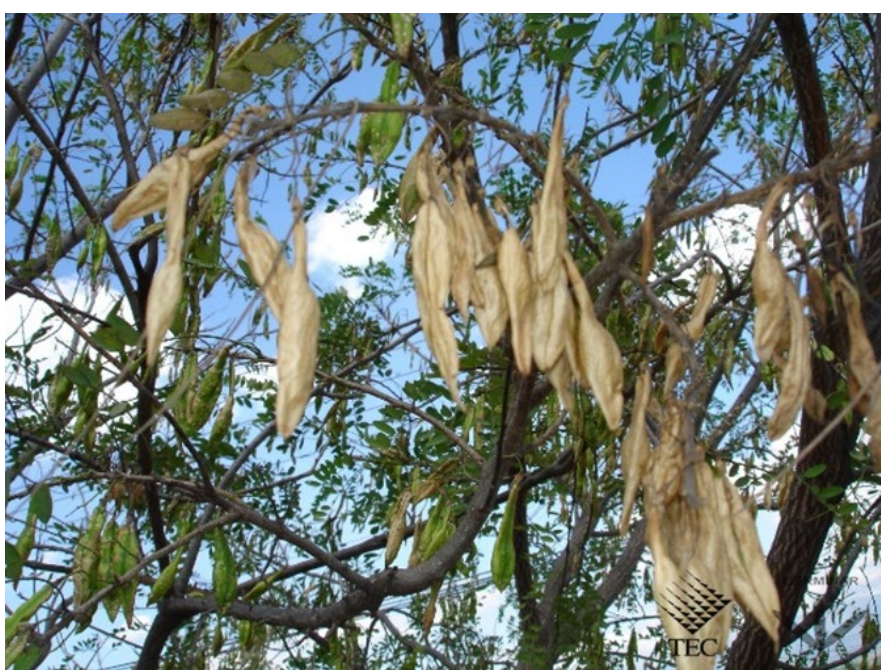

Figura 2. Frutos del Guachipelín.

Figure 2. Fruits of "Guachipelín" tree.

El procesamiento que consiste en eliminar manualmente, o por frotación en seco, las vainas secas que involucran en su sección central las semillas, con lo que se puede llegar a obtener un total de 40717 semillas por kilogramo. Las semillas, dependiendo de su calidad, pueden llegar a un porcentaje de germinación que varía entre un 85 y un $100 \%$. Estas se siembran por el método de puntos o surcos, en un sustrato a base de tierra más arena (en una relación 2:1 respectivamente). Se deben cubrir subsuperficialmente, siendo que la germinación se experimenta entre los 11 y los 19 días después de la siembra [2].

Las plántulas se encuentran listas para su repique o trasplante, bajo el sistema de producción en bolsa plástica, tres semanas posteriores a la germinación. En cuanto al mantenimiento, durante la viverización, es

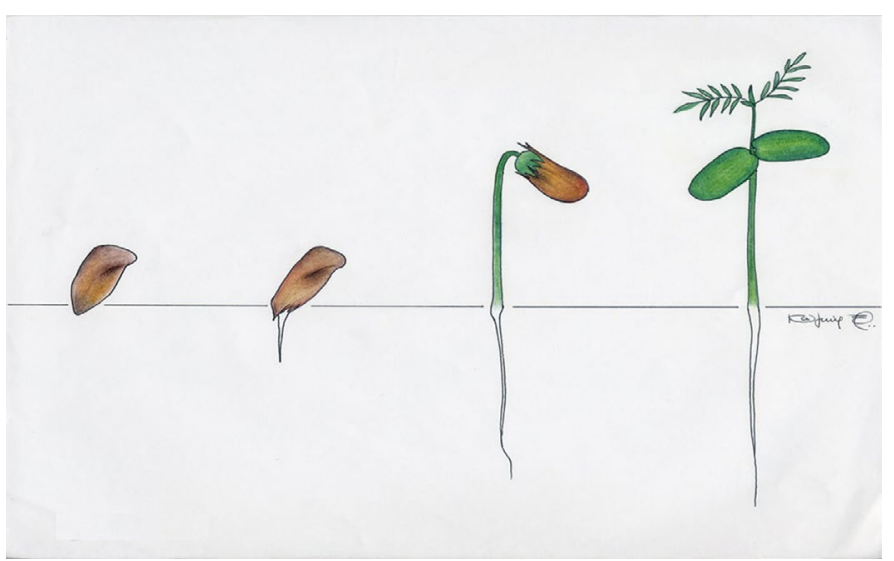

Figure 3. Proceso de germinación del guachipelín.

Figure 3. Seed germination of "guachipelín" tree. recomendable aplicar sombra por un periodo no mayor a los 8 días, así como fertilización química u orgánica en caso necesario [2].

Una vez plantada, esta especie es de crecimiento lento, empieza a producir frutos al cuarto o quinto año. El injerto tipo púa y el acodo aéreo serían opciones de reproducción asexual interesantes para lograr la fructificación al segundo año de plantada [3].

\section{Proceso de germinación}

El tipo de germinación del grumichama es epígea, según la figura 3.

\section{Referencias}

[1] H. Arce, L. Sánchez, J. Slaa, P. Sánchez-Vindas, A. Ortíz, J. van Veen y M. Sommeiijer, Árboles melíferos nativos de Mesoamérica. 1ra edición. Heredia, Costa Rica: Herbario Juvenal Valerio (programas PRAM-CINAT-UNA-UU), 2001.

[2] C. Torres, D. Carvajal, F. Rojas y M. Arguedas, "Reproducción de especies arbóreas y arbustivas de la región central de Costa Rica (Germinar 2)", 2011. Disponible: http://www.tec. ac.cr/sitios/Docencia/forestal/Germinar/germinar\%202. html

[3] V. Alvarado y M. Zúñiga, Plantas nativas para el control de la erosión. 1ra edición. Cartago, Costa Rica: Editorial Tecnológica de Costa Rica, 2018

\section{Este artículo debe citarse como:}

Rojas-Rodríguez, F., \& Torres-Córdoba, G. (2018). Árboles del Valle Central de Costa Rica: reproducción guachipelín (Diphysa americana (Mill.) M. Sousa). Revista Forestal Mesoamericana Kurú, 16(38), 69-71. Doi. org/10.18845/rfmk.v16i38.3998 